\title{
Artigo
}

\section{Tudo muda, nada muda: as implicações do uso das tecnologias de informação sobre o trabalho das mulheres no setor eletroeletrônico*}

\author{
Marcia de Paula Leite** \\ Pilar Carvalho Guimarães***
}

\section{Resumo}

Este texto discute as implicações sociais das novas tecnologias de informação e comunicação (TICs) sobre o trabalho, a partir de uma perspectiva de gênero. Como parte de uma pesquisa realizada pela CEPAL em três países da América Latina, entre os quais o Brasil, ele se baseia em um estudo de caso realizado numa fábrica do setor eletroeletrônico na Região Metropolitana de Campinas, Estado de São Paulo. As conclusões do estudo indicam que, tal como apontado em análises anteriores, o trabalho das mulheres não vem sendo enriquecido com a introdução das novas tecnologias.

Palavras-chave: Tecnologias de Informação e Comunicação (TICs), Setor Eletroeletrônico, Divisão Sexual do Trabalho.

* Recebido para publicação em 29 de agosto de 2013, aceito em 15 de outubro de 2014.

** Professora dos Programas de pós Graduação em Educação e em Ciências Sociais da Unicamp, Campinas, São Paulo, Brasil. mpleite48@gmail.com

*** Mestranda do Programa de Pós Graduação em Educação da Unicamp, Campinas, São Paulo, Brasil. pilarcarvalhoguimaraes@gmail.com 
334 Tudo muda, nada muda

\title{
Everything Changes, Everything Remains. Consequences of The Use of Information Technologies on Women's Work
}

\begin{abstract}
This paper discusses the social implications of new Information and Communication Technologies (ICTs) on labor, from the perspective of gender. As part of a survey carried out by CEPAL in three Latin American countries, including Brazil, it is based on a case study conducted in a factory of the electronics sector in the Metropolitan Region of Campinas. The study's findings indicate that, as pointed out in previous analyses, female labor has not improved with the introduction of new technologies.
\end{abstract}

Key Words: Information and Communication Technologies (ICTs), Electronics Sector, Sexual Division of Labor. 


\section{Introdução}

A difusão das tecnologias de informação e comunicação (TICs) nas sociedades atuais tem gerado um intenso debate sobre suas implicações sociais. Começando pelos estudos voltados à discussão da sociedade do conhecimento e passando por um enorme conjunto de pesquisas destinadas a evidenciar suas consequências para o trabalho, o tema tem sido marcado por uma acirrada controvérsia.

Antes de mais nada, seria importante destacar que o conceito de sociedade do conhecimento é polissêmico $e$ multifacetado, sendo caracterizado sobretudo por sua imprecisão. Conforme alerta Squirra (2005:257), é um conceito de difícil definição, não existindo consenso sobre seu significado.

Baseando-se no entendimento comum a grande parte dos estudiosos de que a sociedade do conhecimento seria aquela em que o conhecimento consiste no principal recurso à produção de riquezas e bem-estar social (Dziekaniak e Rover, 2011), alguns sublinham as implicações sociais positivas dessa sociedade que se está gestando, em que o trabalho tenderia a se tornar cada vez mais mental (Drucker, 1994). Muitos outros, contudo, têm alertado para o fato de que as mesmas tecnologias que estariam na base da sociedade do conhecimento poderiam, de acordo com a maneira como forem aplicadas, ser geradoras de desemprego e do aumento das diferenças sociais, tendo em vista que

a cada momento surgem novidades tecnológicas que são acessíveis apenas para uma camada social, deixando as menos favorecidas ainda mais distantes de crescimento $e$ acesso ao novo tecnológico, que move e direciona a sociedade (Dziekaniak e Rover, 2011:4).

Rifkin (2000) aponta na mesma direção, ao sublinhar que a difusão da informação como conhecimento codificado não ocorre da mesma forma para todos, provocando um abismo entre conectados e desconectados que pode ser maior do aquele que 
sempre existiu entre pobres e ricos. Vários desses estudos têm sublinhado que, assim como antes do surgimento das TICs, o trabalho qualificado tenderia a se concentrar em alguns poucos setores e atividades (Castells, 1999; Schaff, 1996). Estes últimos estudos têm ressaltado a manutenção, quando não a difusão, do trabalho manual, parcelado e repetitivo e não só daqueles/as que trabalham diretamente com as novas tecnologias, mas inclusive daqueles/as que as produzem (Toffler, 1980). É esse o tema que o presente texto aborda, visando contribuir para a discussão a partir de uma análise calcada nas relações sociais de gênero.

Este artigo é resultado de uma pesquisa realizada com o apoio da CEPAL ${ }^{1}$, "Estudio sobre el impacto de las tecnologías en el empleo, la productividad y el bienestar de las mujeres", que ocorreu simultaneamente no Brasil (setor eletroeletrônico), Panamá (call centers) e Peru (empresárias). Nele discutiremos o resultado do trabalho de campo no Brasil, realizado numa fábrica da Região Metropolitana de Campinas (RMC), no Estado de São Paulo, tendo como preocupação central averiguar quais as implicações do uso das novas tecnologias da informação sobre o trabalho das mulheres no setor eletroeletrônico, a partir de um estudo de caso.

O estudo foi realizado a partir de visitas à fábrica $e$ entrevistas com dirigentes sindicais, trabalhadoras, supervisores $e$ gerente de recursos humanos. Os resultados serão comentados nos tópicos a seguir, voltados (1) à discussão da divisão sexual do trabalho na indústria em geral e no setor eletroeletrônico em particular; (2) à análise do setor eletroeletrônico no Brasil; e (3) aos achados da pesquisa. Um último tópico será dedicado à conclusão.

${ }^{1}$ Comissão Econômica para a América Latina e o Caribe. 
1. A divisão sexual do trabalho na indústria

A discussão sobre as implicações das novas tecnologias sobre o trabalho de homens e mulheres não é nova na Sociologia do Trabalho. Desde as contribuições clássicas de Daniele Kergoat (1981, 1984), Cinthia Cockburn (1985) e Helena Hirata (1988), entre outras, têm sido sinalizadas as implicações desiguais dos usos das tecnologias para o trabalho masculino e para o feminino, com destaque para as questões de qualificação, emprego $e$ condições de trabalho em geral. Em um importante estado da arte dessa discussão, Helena Hirata concluía em 1988 que o avanço tecnológico não significava uma melhoria na divisão sexual do trabalho industrial, tendo em vista que as tecnologias eram introduzidas especialmente nos postos de trabalho masculinos e as mulheres permaneciam segregadas nos trabalhos manuais, repetitivos e taylorizados.

Os estudos sobre a divisão sexual do trabalho têm destacado fortemente que a divisão do trabalho na sociedade, que responsabiliza a mulher pelo trabalho reprodutivo e o homem pelo produtivo, está na base da divisão do trabalho remunerado entre homens e mulheres, seja entre os vários setores da economia, seja no interior de cada um deles, incluindo a indústria. Como explicita Elizabeth Lobo:

\begin{abstract}
As hipóteses centradas na diferenciação entre produção $e$ reprodução partem da divisão sexual do trabalho instituído no nível da sociedade, que separa esfera produtivamasculina e reprodutiva-feminina. A divisão das esferas, ao designar prioritariamente as mulheres à esfera reprodutiva, determina a esta papel subordinado na esfera produtiva (Lobo, 1991:48).
\end{abstract}

Isso significa que a divisão social do trabalho entre homens e mulheres se reproduz na divisão sexual do trabalho no interior das fábricas. De fato, já não são poucos os estudos (Kergoat, 1984; Kergoat e Hirata, 2008; Maruani e Hirata, 2003; Leite, 2003; Lobo, 
1991) que têm apontado a segregação das mulheres em atividades menos qualificadas, exercendo trabalhos com pouco conteúdo tecnológico, baixa remuneração e praticamente nenhuma possibilidade de ascensão na carreira, inclusive em indústrias altamente sofisticadas em termos tecnológicos. Relegadas a postos de trabalho manuais e repetitivos, que exigem destreza, agilidade e delicadeza, elas normalmente têm pouco contato com as novas tecnologias, em geral concebidas e manejadas pelos homens. Essa apropriação masculina da tecnologia foi claramente elucidada por Cinthia Cockburn (1985) ao explicar o assenhoreamento da esfera tecnológica por eles e a construção social do feminino como incompetente em termos tecnológicos.

Estudos mais recentes sobre a divisão sexual do trabalho na indústria demonstram a permanência das evidências encontradas pelas pesquisas acima, ainda que em movimentos muitas vezes contraditórios. $\mathrm{O}$ aumento da participação feminina no mercado de trabalho segue convivendo com a segregação $e$ a hierarquização entre postos de trabalho masculinos e femininos; ainda que as diferenças salariais entre homens e mulheres tenham diminuído, as trajetórias profissionais analisadas de maneira sexuada continuam evidenciando disparidades (Bruschini $e$ Lombardi, 2003; Sampaio, 2007; Guiraldelli, 2004; Santos, 2004; Leite e Salas, 2014; Lavinas, 2014).

Esses estudos têm destacado que a desigualdade no uso do tempo fora do trabalho para homens e mulheres persiste $e$ as tarefas domésticas e responsabilidades familiares permanecem relegadas a elas. Conforme elucidam Hirata e Kergoat (2003), ao mesmo tempo em que desigualdades são vencidas, novas fontes de diferenciação e segregação emergem, reconfigurando as disparidades sociais: como não se modifica a divisão sexual do trabalho, que confere a responsabilidade do trabalho doméstico às mulheres, a entrada destas mulheres em funções qualificadas, anteriormente masculinas, é acompanhada pela responsabilização do trabalho doméstico, que era por elas desempenhado, para outras mulheres, gerando uma polarização entre as bem formadas, 
com acesso a empregos qualificados $e$ as que continuam se responsabilizando pelas tarefas domésticas.

Essas tendências significam também a continuidade da segregação das mulheres em alguns setores industriais $e$, no interior das empresas, em determinados postos, nos quais elas desempenham tarefas relacionadas com qualificações naturalizadas, como o trabalho manual, que exige paciência, rapidez e destreza. Como demonstra nosso estudo de caso, a inovação tecnológica e a modernização empresarial não vêm contribuindo para a qualidade do emprego da grande maioria das mulheres na indústria (que continuam desempenhando funções taylorizadas e com exigências de competências não reconhecidas enquanto tais), ainda que esteja ocorrendo o acesso de mulheres mais escolarizadas a postos de gerência, promovendo uma diferenciação no interior da força de trabalho feminina, entre mulheres mais e menos escolarizadas. Conforme explicita Guiraldelli:

Com a divisão social e sexual do trabalho, ocorre uma polarização das qualificações masculinas e femininas, visto que os homens ocupam majoritariamente determinados postos de trabalho, como é o caso da siderurgia $e$ metalurgia, enquanto as mulheres ocupam setores como o têxtil, o comércio, dentre outros marcados pela informalidade e terceirização. Isso pode ser constatado com base em pesquisa realizada no município de Divinópolis, na região centro-oeste de Minas Gerais, que se destaca economicamente pela produção confeccionista/ vestuário e pela indústria metalúrgica. Os dados da Relação Anual de Informações Sociais (RAIS), do ano de 2008, apontam que, no município, dos/as empregados/as formais no setor da metalurgia, 7\% eram mulheres e $93 \%$ homens. Já na indústria da confecção/vestuário, neste mesmo município, havia a incorporação de $73 \%$ de mulheres e $27 \%$ de homens 
no setor, reforçando e sustentando as bases da divisão sexual do trabalho (Guiraldelli, 2004:716).

Ou seja, a divisão sexual do trabalho continua estabelecendo assimetrias, hierarquias e valores diferenciados sobre os trabalhos masculinos e femininos. Sampaio (2007) sublinha essa segregação na Renault, Guiraldelli (2004) no setor de confecção, Santos (2004) no setor calçadista e nós pretendemos demonstrá-la neste estudo de caso do setor eletroeletrônico.

A divisão sexual do trabalho, somada à apropriação masculina da tecnologia, faz com que o trabalho feminino desenvolvido na indústria em geral não seja significativamente modificado com o desenvolvimento tecnológico das empresas e a introdução das tecnologias da informação e comunicação (TIC's).

Esse processo pode ser perfeitamente evidenciado no setor eletroeletrônico, no qual não só a produção se destina a aparelhos de alto conteúdo tecnológico, como a utilização das TIC's na produção tende a ser bastante intensa.

$\mathrm{Na}$ verdade, contrariamente ao que se poderia esperar, a segregação das mulheres em trabalhos absolutamente manuais $e$ destituídos de conteúdo faz com que a utilização das TIC's sirva precisamente para simplificar e controlar as atividades das trabalhadoras aí alocadas, conforme explicita o estudo de caso que apresentamos adiante.

\section{O setor eletroeletrônico no Brasil}

O setor eletroeletrônico possui enorme importância para o desenvolvimento nacional, na medida em que interfere na competitividade de praticamente todos os outros setores da economia brasileira. Atualmente, ele é considerado um dos responsáveis pela difusão das inovações, pelos ganhos de produtividade, redução de custos e estabelecimento dos preços 
finais dos produtos e serviços ${ }^{2}$ (MDIC, 2007). A participação do setor eletroeletrônico no PIB brasileiro foi da ordem de $4,5 \%$ em 2008, evidenciando sua importância para a economia nacional (DIEESE \& CNM/CUT, 2010).

O país vive no momento um aumento significativo da demanda por produtos eletroeletrônicos, fortemente pressionada pelo crescimento dos setores de telecomunicações e informática, exploração de petróleo, energia elétrica e automotivo (Tavares, 2001). O Brasil representa, nesse contexto, um mercado potente. Mas, embora fundamental para o desenvolvimento industrial do país, o setor eletroeletrônico apresenta problemas competitivos, os quais têm afetado a balança comercial. De fato, o setor vem apresentando déficits há vários anos, caracterizados pela importação de componentes - ramo mais dinâmico do setor - $e$ pela exportação de bens finais, em geral, montados no país.

Conforme Balbinot e Marques:

Outro dado importante é a desigualdade do setor eletroeletrônico no Brasil comparado com outros países: a maioria dos países emergentes é superavitária nesse setor. Tavares (2001) informa que Malásia, Singapura, Coréia, Tailândia, Irlanda, México, Indonésia e Costa Rica estão em melhor posição que o Brasil (Balbinot e Marques, 2009:606).

Vale notar, contudo, que a indústria eletrônica brasileira está vivendo no momento um período de expansão. De fato, depois de

2 "Pelo tamanho e, especialmente, pela intensidade do desenvolvimento tecnológico, esta indústria possui efeito multiplicador em diversos outros segmentos da economia: as plantas industriais em geral dependem de equipamentos (como motores), materiais elétricos de instalação e sistemas de automação, $e$ todas as empresas de bens e serviços demandam equipamentos de telecomunicações e de informática. Mais que isso: o país todo depende de equipamentos de geração, transmissão e distribuição de energia elétrica. Portanto, a qualidade e a magnitude da oferta de produtos elétricos e eletrônicos acabam condicionando as operações e a eficiência de outros segmentos da economia e, por isso, a referida indústria é estratégica para o desenvolvimento nacional" (Dieese, 2010:4). 
três décadas sem política industrial, o atual governo lançou várias políticas que têm afetado positivamente o setor, como a Política Industrial, Tecnológica e de Comércio Exterior (PITCE) em 2003, a Lei de Inovação em 2004, a Lei do $\mathrm{Bem}^{3}$ em 2005 e a Lei da Informática ${ }^{4}$ revisada. Os investimentos em C\&T têm crescido anualmente desde 2000 e os financiamentos de subvenção à inovação na empresa foram iniciados em 2006 (www.mct.gov.br).

Em termos de inovação tecnológica, alguns ramos representativos da indústria eletrônica (máquinas de escritório e equipamentos de informática; máquinas, aparelhos e materiais elétricos; material eletrônico e aparelhos e equipamentos de comunicações; equipamentos de instrumentação médicohospitalares, instrumentos de precisão e ópticos, equipamentos para automação industrial, cronômetros e relógios) são classificados como os mais inovativos do país (Ansanelli, 2010:142).

A taxa de inovação média desses segmentos, em conjunto, foi superior a 50\% no período 2003-2005, ultrapassando a verificada pela indústria de transformação em geral, que correspondeu a 33,4\% em 2005. Desde 1998 esses segmentos vêm sendo classificados nos níveis de alta e média alta intensidade tecnológica (IBGE, 2007, apud Ansanelli, 2010:142). Nesses ramos, as atividades inovativas absorveram entre 3,8\% e 5,3\% da receita líquida de vendas no período e gastaram mais de $1 \%$ da receita líquida com P\&D internos, superando a parcela, como um todo,

${ }^{3}$ Lei $\mathrm{n}^{\mathrm{o}} 11.196$, de 21 de novembro de 2005 [http://www.planalto.gov.br/ccivil_03/_Ato2004-2006/2005/Lei/L11196.htm].

Essa Lei, que ficou conhecida como Lei do Bem, cria a concessão de incentivos fiscais às pessoas jurídicas que realizarem pesquisa e desenvolvimento de inovação tecnológica.

${ }^{4}$ Lei $\mathrm{n}^{\circ}$ 8.248, de 23 de outubro de 1991 [http://www.planalto.gov.br/ccivil_03/leis/18248.htm]. Essa Lei, que ficou conhecida como Lei da Informática, concede incentivos fiscais para empresas produtoras de alguns hardwares específicos e que tenham por prática investir em Pesquisa e Desenvolvimento. O incentivo concedido é uma diminuição do Imposto sobre Produtos Industrializados (IPI). Como contrapartida, a empresa deve investir um percentual de seu faturamento decorrente dos produtos incentivados em atividades de Pesquisa e Desenvolvimento de Produtos. 
da receita da indústria. Eles não só têm dedicado uma parcela elevada da receita a $\mathrm{P} \& \mathrm{D}$, mas também possuem significativa participação nas aquisições de máquinas (IBGE, 2007, apud Ansanelli, 2010:142). Mas, embora seja muito inovador, o complexo eletrônico brasileiro ainda apresenta fragilidades competitivas e se encontra à margem da fronteira tecnológica mundial.

O principal polo brasileiro de produção eletroeletrônica encontra-se na Zona Franca de Manaus, criada em 1967, com a finalidade de incentivar as atividades econômicas da região norte do país. A região de Campinas, no interior do Estado de São Paulo, constitui um polo também importante de empresas do setor.

A região se desenvolveu industrialmente seguindo $\mathrm{o}$ crescimento da capital do estado, sobretudo a partir dos anos 1970, devido aos importantes impactos que as políticas adotadas pelo governo federal, visando à desconcentração industrial, a partir de 1964, causaram no território paulista. O processo de desconcentração industrial intensificou-se na década de 1980 a partir da dispersão das indústrias para o interior paulista, com destaque para os municípios localizados ao longo dos eixos rodoviários (Marighetti, 2011:3).

Com isso, as cidades do interior paulista, principalmente as médias, assumiram novos papéis na rede urbana local, outrora designados à capital do estado, seja através da diversificação de sua economia, seja pela formação de grandes centros polarizadores de atividades industriais. Nesse contexto, o interior paulista assume o segundo espaço industrial do país, superado apenas pela Região Metropolitana de São Paulo (Lencioni, 2003:466).

Além da atuação do governo federal, não podemos esquecer a participação dos governos estaduais, a partir dos anos 1970, para a descentralização das atividades industriais, visto que os intensos efeitos da concentração industrial na metrópole paulistana já eram objeto de preocupação dos órgãos de planejamento urbano. 
Nesse quadro, as indústrias de alta tecnologia avançam no território na medida em que a própria tecnologia se difunde pelo espaço geográfico, num processo intensificado pela globalização. A integração dos mercados, a participação do Estado, a iniciativa empresarial $e$ a proximidade dos centros de pesquisa $e$ desenvolvimento se tornam novos elementos para se compreender os fatores locacionais, conforme explicita Marighetti (2011:10).

Um bom exemplo de readaptação de fatores locacionais diz respeito à mão-de-obra. As empresas buscavam minimizar os gastos relativos à contratação de trabalhadores alocando suas unidades fabris em territórios onde a mão-de-obra fosse abundante e, muitas vezes barata.

Atualmente, com a dispersão das indústrias de alta tecnologia, esse fator perde relevância e a proximidade com centros de produção tecnológica adquire maior importância.

Nesse sentido, o papel das universidades e dos centros de pesquisa se torna fator atrativo para os empreendimentos, visto que o desenvolvimento ou aprimoramento de tecnologias necessita de infraestrutura adequada.

Estima-se que aproximadamente 348 mil trabalhadores/as estejam envolvidos/as dentro da complexidade do setor eletroeletrônico brasileiro. Esses números representam aproximadamente $20 \%$ dos/as metalúrgicos/as brasileiros/as. Desse total, $92,1 \%$ estão concentrados/as em seis estados (São Paulo, Amazonas, Paraná, Santa Catarina, Minas Gerais e Rio Grande do Sul). Além disso, é preciso destacar que aproximadamente metade dos postos de trabalho do setor está alocada no Estado de São Paulo, o estado com maior contribuição no PIB brasileiro (DIEESE \& CNM/CUT, 2010).

De acordo com estudo do Departamento Intersindical de Estatística e Estudos Socioeconômicos sobre o setor:

As corporações em posição de liderança na eletrônica possuem, via de regra, uma estrutura produtiva verticalizada (forte terceirização) e uma rede bem 
estabelecida de fornecimento de insumos. A forma como essas grandes corporações se estruturam no plano mundial busca aproveitar ao máximo daquilo que as diferentes nações podem lhes proporcionar, ou seja: mercado consumidor, ambiente tecnológico, incentivos fiscais, condições macroeconômicas favoráveis à exportação e, em especial, reduzidos custos trabalhistas para segmentos intensivos em mão-de-obra (DIEESE \& CNM/CUT, 2010:3).

As estratégias das principais empresas do setor, de acordo com estudo do DIEESE \& CNM/CUT, são:

1) Estratégia de liderança tecnológica, caracterizada por inovações radicais ou incrementais; obtenção de ganhos mediante altas taxas de crescimento dos mercados e manutenção de margens de lucro elevadas; e ocupação de faixas de mercado cujo dinamismo tecnológico e a rentabilidade sejam maiores.

2) Estratégia de baixo custo, baseada em linhas de produção mais intensivas em trabalho, voltadas para faixas de produtos de menor valor no mercado; nesses casos, as empresas buscam ganhos mediante elevadas escalas de produção de mercadorias baratas produzidas com tecnologia madura, para compensar as baixas margens de lucro.

3) Estratégia intermediária, que busca: ocupar estratos intermédios do mercado mediante a produção de bens de tecnologia relativamente disseminada; conquistar espaços subaproveitados pelas companhias de ponta; diluir seus custos e dirimir gradativamente o hiato proporcionado pelo rápido deslocamento da fronteira tecnológica no âmbito internacional; dar um salto tecnológico e industrial associado a esforços de fixação de marca.

As corporações que atuam no Brasil tendem a se concentrar na estratégia intermediária apresentando, via de regra, as seguintes características:

(a) estreitas ligações com a matriz ou com a empresa cedente da tecnologia; 
(b) a presença de um mercado consumidor interno diversificado;

(c) dificuldade em ofertar, de forma competitiva, mercadorias de menor valor, em particular as portáteis, devido à concorrência asiática. Além disso, no que diz respeito à tecnologia própria brasileira, em geral, o que temos são produtos de tecnologia simples (DIEESE \& CNM/CUT, 2010:4).

Apesar de expectativas otimistas para o setor nos últimos anos, o complexo eletrônico tem sido tema de preocupação, principalmente pela necessidade de o país gerar superávits comerciais tendo em vista o déficit na balança comercial que o setor tem apresentado. Embora seja possível perceber um aumento contínuo nos fluxos internacionais do setor no decorrer dos anos, o ritmo de crescimento das importações é maior do que o do crescimento das exportações. Relacionada a esse fator, está a necessidade de investimento em segmentos e componentes intensivos em tecnologia, que são importados.

Apesar do alto conteúdo tecnológico da produção eletroeletrônica, 60,9\% dos/as trabalhadores/as nela alocados/as possuem ocupações em áreas manuais, $15 \%$ em áreas administrativas, $13,7 \%$ em ocupações de nível técnico (médio e superior) e 7\% em áreas de apoio; 37\% dos/as trabalhadores/as estão concentrados/as em empresas de grande porte, $33 \%$ em empresas de médio porte, $30 \%$ em empresas de pequeno porte (DIEESE \& CNM/CUT, 2010).

$\mathrm{O}$ número de trabalhadores/as do setor eletroeletrônico passou por profundas mudanças nos últimos 15 anos. Com exceção do ano 2000, que apresentou um crescimento no número de emprego, a regra geral foi a queda do número de postos de trabalho de 1996 a 2002, quando 44\% dos postos de trabalho foram eliminados (DIEESE \& CNM/CUT, 2010:18).

A partir de 2003 o setor voltou a crescer e até dezembro de 2006 havia recuperado 32,8\% do nível de emprego. Em 2007 foi observada novamente queda e desde então um ligeiro crescimento anual. Entretanto, ainda existe uma grande distância 
em relação aos números observados durante a década de 1990 (DIEESE \& CNM/CUT, 2010:18).

A jornada média contratual dos/as trabalhadores/as do setor é de 43,4 horas semanais. O tempo médio de casa no atual emprego é de 1 a 2 anos para 20,3\% dos/as trabalhadores/as, 5 a 10 anos para $12 \%$ e de 6 meses a 1 ano para 15,8\%; 56,3\% dos/as trabalhadores/as do setor possuem o segundo grau completo, $18,7 \%$ possuem a $8^{a}$ série completa e cerca de $7,7 \%$ não possuem sequer esse título. Praticamente metade dos/as trabalhadores/as tem até 30 anos e a outra metade, acima de $30 .^{5}$

As mulheres representam $33 \%$ do total de trabalhadores do setor e o salário é $\mathbf{3 2 \%}$ menor em relação ao dos homens. ${ }^{6}$ Alguns estudos sobre o trabalho no setor indicam que a mão de obra feminina vem sendo incorporada com maior intensidade às áreas automatizadas da produção, sem que isso signifique melhoria da sua qualificação. Oliveira, por exemplo, analisa o aumento do trabalho feminino no setor em empresas da Zona Franca de Manaus da seguinte forma:

as empresas promoveram um enxugamento dos setores automatizados. Boa parcela de trabalhadores foi substituída por mulheres; ao mesmo tempo, provocou-se um esvaziamento de conteúdos, com a simplificação do trabalho. A mão de obra feminina é treinada apenas para as operações de supervisão dos equipamentos. Os trabalhos de manutenção técnica são realizados por técnicos $e$ engenheiros - todos homens. Há, sem dúvida, uma associação bastante recorrente entre trabalho feminino $e$ postos taylorizados (Oliveira, 2006:704).

A Região Metropolitana de Campinas vem se configurando nos últimos anos como um polo do setor eletroeletrônico do

5 Dados obtidos em entrevista com o Presidente do Sindicato dos Metalúrgicos de Campinas.

6 Dados disponíveis na página da Central Única de Trabalhadores (CUT) [http://www.cnmcut.org.br/conteudo/perfil-dos-trabalhadores-3 - acesso em: nov. de 2013]. 
Estado de São Paulo, contando atualmente com 3.400 empresas das áreas de telefonia, máquinas, autopeças, fundições, montagem e tecnologia da informação, de acordo com os dados do Sindicato dos Trabalhadores Metalúrgicos da Região.

O setor da metalurgia, do qual o eletroeletrônico faz parte, acomoda 81 mil trabalhadores na região, sendo $79 \%$ homens $e$ $21 \%$ mulheres, entre as 9 cidades da região. No setor eletroeletrônico especificamente, a composição é de $59 \%$ de mulheres e $41 \%$ de homens. ${ }^{7}$ Por ser um setor com alto uso de tecnologias e com maioria de trabalhadoras, analisaremos neste artigo as implicações do uso dessas tecnologias sobre as condições de trabalho das mulheres de uma fábrica do ramo da telefonia da Região Metropolitana de Campinas.

Uma característica do setor que chama a atenção na região é a quantidade de empresas asiáticas: japonesas, chinesas, coreanas etc. Essa origem tem um forte impacto nas estratégias de gestão da mão de obra, com muita segregação do trabalho feminino e assédio moral.

\section{A pesquisa}

A fábrica visitada no Brasil é subsidiária de uma multinacional norte-americana que produz aparelhos eletrônicos como celulares, tablets, nextel e acessórios. A planta foi inaugurada em 1996 e conta, em sua unidade situada na Região Metropolitana de Campinas, com 1900 trabalhadores/as no setor de produção. $\mathrm{O}$ empreendimento foi recentemente incorporado a outra rede de capital internacional e sofreu algumas alterações na organização de suas funções. Ainda assim, os/as supervisores/as entrevistados/as ${ }^{8}$ atestaram não ter havido mudanças significativas

7 Dados do Sindicato de Metalúrgicos de Campinas e região [http://www.metalcampinas.org.br/ - acesso em: nov. de 2013].

8 A pesquisa, realizada em setembro de 2012, contemplou oito entrevistas com trabalhadoras da produção, uma entrevista com um supervisor de produção $e$ outra do setor de saúde no trabalho, uma entrevista com a gerente de recursos 
na estrutura interna da unidade de São Paulo, assim como um número mínimo de demissões. Com a nova administração, algumas inovações foram relatadas, tais como maiores possibilidades de promoção de funcionários/as e a criação de espaços de lazer na fábrica.

As relações de trabalho entre funcionários/as foram avaliadas como "abertas ao diálogo" pelos supervisores/as que disseram "eles nem têm problema aqui; falou em restaurante legal, a gente tem; transporte legal, a gente tem; ergonomia, a gente tem; é uma relação tranquila". Os/as supervisores/as também fizeram questão de frisar as grandes possibilidades de plano de carreira no interior da fábrica, informação que foi contestada por sete das oito trabalhadoras entrevistadas; para elas, as possibilidades de ascensão são mínimas, se não inexistentes. $\mathrm{O}$ layout da fábrica comporta uma grande quantidade de cartazes, sinais, dizeres e slogans que remetem à produtividade e à dedicação à empresa, tanto no saguão de entrada quanto no restaurante, em corredores e chão de fábrica. As trabalhadoras relataram ainda que o Sindicato dos Trabalhadores ligado a essa empresa é mais patronal do que operário, sendo condizente com as decisões da direção da empresa e não atuando como agente formador e potencializador de discussões entre os trabalhadores.

Vale destacar que as lideranças sindicais que entrevistamos estão ligadas a outra entidade, o Sindicato dos Trabalhadores Metalúrgicos da Região Metropolitana de Campinas, notoriamente mais engajado politicamente no debate sindical do estado ${ }^{9}$. As

humanos. Entrevistamos ainda o presidente, uma diretora e uma trabalhadora sindicalizada da base do Sindicato de Trabalhadores Metalúrgicos da RMC.

9 Essa não coincidência entre o sindicato entrevistado e o sindicato ao qual a empresa em questão está relacionada explica-se pela dificuldade de acesso às fábricas no início da pesquisa devido à complexa conjuntura marcada, de um lado, pelas campanhas eleitorais municipais e estaduais e, de outro, pela negociação coletiva do setor. Este último fato foi responsável por uma forte mobilização dos trabalhadores, inclusive com paralisação da produção em algumas empresas. Frente a essas dificuldades, decidiu-se começar a pesquisa com as entrevistas junto à direção do sindicato que, por ser uma entidade da Região Metropolitana de Campinas, imaginávamos que abarcava todas as 
informações que temos sobre os/as trabalhadores/as sindicalizados/as advêm das entrevistas com os/as sindicalistas da Região Metropolitana de Campinas. Para o presidente do Sindicato, o uso de novas tecnologias não traz efeitos sobre a qualificação dos trabalhadores do setor. De acordo com ele, embora as máquinas tenham se sofisticado, o trabalho continua sendo repetitivo e muito manual. Essa questão pôde ser confirmada nas entrevistas com as trabalhadoras e, sobretudo, com a gerente de recursos humanos para quem:

\begin{abstract}
na linha de produção tudo é informatizado para que o trabalhador aperte um botão e a coisa já saia pronta (...) as tecnologias estão na empresa inteira, mas são concebidas para facilitar o trabalho dos operadores; os procedimentos operacionais são todos definidos anteriormente.
\end{abstract}

Para o presidente do sindicato, o avanço das tecnologias não está trazendo melhorias sociais, acarretando, pelo contrário, um aumento da carga de trabalho. O processo de trabalho a seu ver continua sendo desvalorizado e o/a trabalhador/a atua mais como personagem do que como sujeito, o que seria uma das razões da alta rotatividade do setor e da dificuldade do processo de formação e do despertar da consciência crítica desses/as trabalhadores/as. Ainda de acordo com ele, "as empresas trazem consigo o idioma e a práxis do seu país de origem, contratam jovens em seus primeiros empregos, hoje com vigor, possivelmente descartáveis no futuro", não oferecendo assim, em sua opinião, melhores condições de trabalho e nem de maior qualificação. Essas opiniões do presidente são compartilhadas pela diretora entrevistada que sublinha as más condições de trabalho no setor, sobretudo para as mulheres. Segundo ela, a preocupação dos militantes agora é o fortalecimento de um Coletivo de Gênero para direcionar a luta por melhores condições

empresas da região. Só quando começamos as entrevistas com as trabalhadoras é que nos demos conta de que a empresa fazia parte de outra base sindical. 
de trabalho, especialmente as relacionadas às condições de saúde. Para ela:

não há formação, nem capacitação. Não há possibilidade de diálogo, mas há cargos de liderança, nos quais as mulheres são maioria; agora, as possibilidades de ascensão existem, se você obedecer as regras e não for do sindicato.

De acordo com essa diretora sindical, o Coletivo vem também trabalhando pelo aumento da licença paternidade e pela concessão de licença de casamento para casais homoafetivos. Isso foi confirmado pela gerente de recursos humanos da fábrica, que afirma que os "treinamentos são mais para líderes e funcionários da área administrativa".

$\mathrm{Na}$ verdade, a pesquisa revelou grandes dificuldades de formação para os/as trabalhadores/as do chão de fábrica. A estratégia para contratar as trabalhadoras não está relacionada com carreira, qualificação, possibilidade de ascensão profissional, mas a outros critérios que se baseiam, por exemplo, nas responsabilidades femininas como a manutenção da família. De acordo com a gerente de recursos humanos, a única exigência para as contratações é o segundo grau completo e um dos mais importantes critérios da seleção de pessoal é de privilegiar

mulheres casadas ou solteiras com filho, que têm necessidade do trabalho, para evitar o absenteísmo. (...) o que é mais valorizado nas entrevistas de seleção e de promoção é o comportamento, ambições e aspirações. No treinamento comportamental frisamos que é o trabalho que propicia a realização dos sonhos, porque às vezes eles não percebem isso.

Ressalte-se ainda que apesar de a empresa privilegiar mulheres com filhos pequenos na contratação, não há qualquer programa no sentido de auxiliar a compatibilização entre o trabalho reprodutivo realizado no âmbito privado da vida dessas mulheres e o trabalho realizado na empresa; "são três turnos de 
trabalho e as pessoas devem organizar sua vida em função disso", diz a gerente de recursos humanos.

Grande parte dos insumos utilizados pela empresa é originária de países asiáticos, como Japão e China. São eles: microssensores inseridos nas placas de rede, chips que compõem os aparelhos celulares, componentes eletrônicos inseridos nas placas de circuito. As matérias-primas (minério de ferro, cobre e outros minerais) são nacionais, mas são enriquecidas fora do Brasil. Empresas brasileiras exportam esses minérios para os países asiáticos, que os transformam em componentes eletroeletrônicos e os vendem novamente ao país.

A planta da fábrica está dividida em três grandes áreas: front end, back end e centro de recuperação de componentes $e$ aparelhos (CAR). A inclusão do trabalhador em determinado setor da produção é evidenciada através da cor de seu avental. Há um rígido protocolo a ser seguido para viabilizar a entrada das pessoas no setor de produção, todo ele direcionado para o cuidado de não danificar os aparelhos e insumos presentes no ambiente. Para a entrada dos funcionários e de quaisquer visitantes no chão de fábrica, são utilizados aventais, toucas, calcanheiras e pulseiras. Em seguida, passa-se por um detector de metal e por testes realizados em computador para verificar o uso correto desses protetores. Linhas coloridas coladas ao chão indicam os únicos caminhos possíveis dentro da planta e por todo lado há o plano de carreira em grandes cartazes, como incentivo para o crescimento dos/as trabalhadores/as dentro da empresa, apesar de, conforme já esclarecido, as entrevistadas terem relatado uma enorme dificuldade para ascensão na carreira.

No front end, considerado pelo supervisor que direcionou nossa visita como o "gargalo da produção" - aquele setor que determina o volume da produção da unidade, pois seria mais oneroso produzir a placa do que montar os aparelhos -, trabalham homens majoritariamente. É nesse setor que são produzidas as placas que comporão os aparelhos eletrônicos. Cada linha do front end conta com 4 operadores e produz em média 90 placas por hora, de forma totalmente automatizada; cada tipo de placa 
será inserida posteriormente em celulares, nextel, tablets ou modens.

Do front end, as placas seguem para o warehouse, onde são catalogadas e armazenadas e seguem para abastecer o back end, constituído por postos de trabalhos para a montagem e encaixe dos componentes. Cada linha do back end conta com 60 operadoras e produz em média de 300 a 350 aparelhos por hora. Trabalham nesses postos mulheres que exercem atividades absolutamente manuais, distribuídas em linhas de montagem seccionadas. Cada uma executa uma função rápida $e$ repetitiva, utilizando menos de cinco minutos em média em cada aparelho, contando com instruções logo acima da linha dos olhos, para evitar qualquer lapso da memória. Uma das trabalhadoras entrevistadas relata: "Como é um trabalho muito repetitivo, às vezes a gente precisa fazer força pra não fechar os olhos". Essas trabalhadoras trocam de função de 2 em 2 horas com o objetivo de prevenir as lesões por esforço repetitivo. A rotação de funções não significa, entretanto, qualquer enriquecimento do trabalho, tendo em vista que todos os postos do back end são manuais $e$ absolutamente destituídos de conteúdo, revelando uma alienação das operadoras em relação ao trabalho que realizam. O último posto do back end é o de testes, aplicados por softwares computadorizados.

Caso os testes evidenciem algum dano ou problema no aparelho produzido no back end, seja ele um aparelho celular, nextel, modem ou tablet, o produto é encaminhado ao CAR, centro de reparos da fábrica, onde o equipamento será analisado por um técnico eletroeletrônico (quase sempre homem) que identifica o problema e encaminha para uma reparadora (quase sempre mulher), que irá reparar o componente específico danificado. Cabe destacar que a preferência por mulheres nessa função, tal qual em todos os postos do back end, foi justificada pela "natureza delicada e atenciosa das mulheres, pois o CAR exige uma coordenação fina", de acordo com a gerente de recursos humanos da fábrica. 
Uma vez aprovado pelo controle de qualidade, o equipamento produzido será encaminhado para uma empresa terceirizada, localizada dentro da planta, que embalará e programará o equipamento, deixando-o pronto para a comercialização. O repasse dessa operação para uma empresa terceirizada foi realizado em 2001.

A empresa trabalha por demanda, pois os tipos de aparelhos produzidos não permitem grande armazenamento. Dessa forma, a produção da fábrica oscila bastante, assim como suas contratações. Essa rotatividade foi apontada por uma das operadoras como um fator que aumenta a competição entre os/as funcionários/as que veem assim o seu posto de trabalho em constante ameaça, com o receio de perder o emprego sempre presente.

Houve muitas menções à terceirização da contratação de operadores/as. De acordo com a gerente de recursos humanos, $80 \%$ da mão de obra da fábrica, até muito recentemente, era contratada por uma empresa internacional de contratação de mão de obra temporária. ${ }^{10}$ Essa estratégia da empresa foi confirmada pelas entrevistas realizadas com as trabalhadoras. Segundo elas, os/as trabalhadores/as contratados/as pela terceira passariam por um estágio probatório de três meses e, caso fossem efetivados/as, deveriam ainda passar por mais outros três meses de experiência; somente depois disso passariam a ser contratados/as definitivamente pela empresa em questão. Todas as trabalhadoras que entrevistamos foram contratadas através dessa empresa terceira.

Em 2011, o empreendimento sofreu um TAC (Termo de Ajuste de Conduta) do Ministério do Trabalho que o obrigou a baixar a porcentagem de trabalhadores temporários para $20 \%$. A explicação da gerente de Recursos Humanos do porque eles se

\footnotetext{
${ }^{10}$ De acordo com um supervisor, a empresa estava tentando diminuir o número de trabalhadores/as contratados/as pela terceira, em virtude do alto índice de absenteísmo dos/as trabalhadores/as indiretos/as. A atual porcentagem de terceirizados não foi todavia declarada.
} 
utilizavam dessa estratégia foi a seguinte: "os temporários e trabalhadores por tempo determinado ganhavam o mesmo que os efetivos, mas a empresa ganhava flexibilidade numérica, o que é importante por causa da sazonalidade do produto". Uma das trabalhadoras lembra:

quando eu entrei eu acho que era $70 \%$ de temporário e era uma minoria de efetivo, quando eu entrei em 2010, parece que tinha tido alguma coisa no Sindicato, que parece que eles cortaram isso e que a empresa tinha que ter mais efetivo do que temporário. Mas eu já trabalhei aqui de tipo assim chegar uma certa hora e você ver uma linha inteira saindo porque era temporário...

Outra operadora pondera:

o ambiente de trabalho é competitivo por causa da rotatividade, as pessoas entram sempre como terceiras $e$ ficam muito inseguras [e] a maior parte da força de trabalho quem contrata é a empresa terceirizada, ela contrata por 3 meses e pode renovar por mais três meses e aí efetiva ou manda embora. Aí tipo assim: se você é efetivada, você passa a trabalhar para a empresa e tem mais três meses de experiência. Vai entender né...

Segundo a própria gerente de recursos humanos, o absenteísmo aumentou muito durante esse período, assim como o envolvimento dos/as trabalhadores/as diminuiu; por isso, e por causa do TAC, a porcentagem de trabalhadores/as terceirizados/as diminuiu.

Essas características da fábrica pesquisada evidenciam as observações anteriores sobre a divisão sexual do trabalho: mesmo quando alocadas no trabalho industrial, as mulheres são segregadas em postos menos qualificados, nos quais muito comumente desenvolvem trabalhos manuais, pouco complexos, repetitivos e com escassas possibilidades de qualificação (Helena Hirata, 1988, 2002; Elizabeth Lobo, 1991; Marcia Leite, 2003; Marcia 
Leite e Cibele Rizek, 1998). O alerta da gerente de recursos humanos corrobora a análise:

é uma empresa muito tecnológica, mas na hora da produção é tudo muito facilitado, é tudo programado pra facilitar o trabalho do operador. Os testes que ele faz lá quando ele vai montar o celular, é tudo muito facilitado, ele tem os procedimentos já definidos na bancada de trabalho, os procedimentos operacionais pra aquele modelo, pra aquele produto. Então realmente é tudo muito fácil, quando o produto vai pra linha, é muito fácil de fazer acontecer (...) é um trabalho rotineiro...

No mesmo sentido vão os relatos das trabalhadoras entrevistadas:

a atividade do posto de trabalho é muito fácil, nem precisa de treinamento; mas é muito chato, muito repetitivo;

a gente até troca de função na linha, de 2 em 2 horas, mas o trabalho é quase igual, não muda muita coisa, não;

quando a gente vai mudar de aparelho, aí vem uma pessoa e passa pra gente; é esse o treinamento que a gente tem, é rápido porque é pouca coisa que você faz nos postos; é uns cinco minutos, porque ou você coloca o parafuso, ou a borrachinha, ou o display, então é rápido. Eu acho que seria bom mais qualificação porque você faz, mas não sabe porque, aí você não sabe se tá bom, se vai falhar. Fica meio vago o que a gente faz.

Esses relatos das trabalhadoras evidenciam que ainda que o resultado do trabalho que elas realizam seja altamente tecnológico, elas não fazem uso dessa tecnologia e quase não têm contato com ela. Além disso, as condições de trabalho não propiciam oportunidades de conhecimento e ascensão, conforme já explicitado e corroborado pelas declarações a seguir: 
eles esquecem que a gente é uma pessoa;

eles falam que tem bastante curso aqui, mas a gente mesmo não fica sabendo quando vai ter, só sabemos quando aparece alguém com o diploma;

eu vou lá, eu conheço as pecinhas, eu monto; agora não me fala o que ele $e^{11}$ faz que eu não sei, não me fala pra que ele serve que eu não sei, eu não procuro saber, eu faço o meu;

ah, o treinamento é assim: elas vêm, faz, te ensina como faz; em questão de cinco minutos. Você vê fazendo... o treinamento aqui nos postos são de minutos, não são difíceis de aprender, os postos;

eu acho que a empresa deveria dar mais oportunidade pra você aprender alguma outra coisa, pra você não ficar naquela mesmice ali;

aqui eu acho que não tem possibilidade de mudar de posto não;

eu não consigo enxergar grandes possibilidades aqui dentro de crescer, se quer crescer tem que ir fazer outra coisa;

o plano de trabalho, sinceramente, é mais pra quem é o queridinho, que tá sempre ali do lado, que faz sempre o que ele pede. Porque quem realmente trabalha direito $e$ não gosta dessas "puxa-saquices", continua no que tá, no máximo operador $2^{12}$.

\footnotetext{
${ }^{11}$ A trabalhadora se refere aqui aos aparelhos que ela monta.

12 Os/as operários/as entram sempre como operador/a 1. O cargo de operador/a 2 é a única possibilidade de ascensão na carreira que a empresa oferece no nível operacional. Depois disso, a ascensão passa pela entrada na estrutura hierárquica da fábrica, como encarregado/a ou supervisor/a. O/a operador/a 2 ganha por volta de $20 \%$ mais do que um/a operador/a 1.
} 
Faz-se necessário destacar o importante papel do conceito de divisão sexual do trabalho na distribuição das tarefas dessa fábrica. É extremamente nítida a separação do trabalho entre homens e mulheres na produção: homens manejando máquinas pesadas e mulheres na montagem, fazendo movimentos rápidos e repetitivos, organizados de forma bastante taylorizada. As mulheres cumprem funções que não exigem nenhuma qualificação, não são ensinadas a manejar equipamentos mais modernos, e quando o são, a justificativa é a sua destreza, sua gentileza, a atenção ao detalhe. Foi possível presenciar a naturalização e a reprodução da noção social de sensibilidade feminina levada ao extremo, seja na assignação das tarefas de montagem às mulheres no back end, seja na segregação das mesmas nas atividades de reparação no CAR.

Vê-se, portanto, neste estudo de caso a nítida divisão do trabalho masculino e feminino, entre tarefas dos homens e das mulheres, entre as atividades que lidam com a tecnologia $e$ as manuais. Ao se apoiar na naturalização de características femininas, essa divisão do trabalho se baseia na separação entre trabalho reprodutivo e produtivo, evidenciando a apropriação masculina do uso das tecnologias, conforme explicitado no primeiro tópico deste texto.

Ou seja, a distribuição das funções por sexo passa necessariamente por um mecanismo cultural, construído historicamente. Assim como se definem "atividades femininas" $e$ "masculinas", inscrevem-se relações de hierarquia, de qualidade e qualificação, com representações distintas de responsabilidade, adequação, possibilidade ou não de aprendizado, as quais remetem às relações de poder fundidas na sociedade. A divisão do trabalho existente na fábrica visitada configura-se como um forte testemunho desse modelo.

\section{Conclusão}

A análise da visita à fábrica, assim como das entrevistas realizadas, nos revela uma realidade em que o uso das TICs não 
só vem tendo pouquíssimas consequências sobre as trabalhadoras, no que se refere à utilização de um trabalho mais qualificado $e$ criativo, como, o que é pior, vem reforçando a divisão sexual do trabalho.

A divisão do trabalho na fábrica se dá de tal forma que quem efetivamente trabalha com as novas tecnologias são os homens; o trabalho das mulheres é absolutamente manual, de montagem, e elas não têm acesso à tecnologia. $\mathrm{O}$ produto de seu trabalho é de alta tecnologia, mas o seu trabalho não. No front end, são os homens que operam e dominam grandes máquinas; as mulheres são alocadas nas linhas de montagem em razão da naturalização da delicadeza e da atenção. Essa divisão sexual do trabalho também se dá na hierarquização das funções. Por exemplo, na área do CAR (de reparo dos aparelhos com falhas) a maioria absoluta é de mulheres, entretanto são os homens que detêm os cargos de chefia, são eles os engenheiros, chefes ou líderes que têm grau técnico em eletrônica e que detectam os problemas nos aparelhos com defeito; elas são relegadas aos postos de trabalho manual de substituição das peças com defeito ou de remontagem de peças mal montadas.

Nesse sentido, podemos dizer que as conclusões de nosso estudo de caso corroboram as mesmas a que chegou Hirata (1988) no estado da arte realizado há 25 anos.

Mas essa análise não nos deve levar à conclusão de que a situação dos operários seja diametralmente oposta a das operárias. Na verdade, a forma de organização do trabalho na fábrica não pressupõe um trabalho mais qualificado nem para elas, nem para eles. Embora os homens predominem nas máquinas e no trabalho de análise de defeito dos aparelhos, nem num caso, nem no outro, pode-se dizer que desempenhem um trabalho criativo, qualificado e enriquecedor.

Essa baixa exigência de qualificação tem a ver com dois fatores. De um lado, a forma de organização do trabalho na fábrica, que continua seguindo os princípios tayloristas de divisão do trabalho, de execução e concepção. Restritos às atividades de execução, os operários manejam máquinas modernas de forma 
totalmente alheia ao seu funcionamento, como deixa claro a gerente de recursos humanos ao afirmar que "a tecnologia é usada para facilitar o trabalho do operador". O mesmo acontece com o trabalho dos que detectam os defeitos dos aparelhos já produzidos no CAR, que seguem normas e procedimentos definidos pela gerência para a detecção de problemas geralmente semelhantes que ocorrem em uma produção pouco diferenciada. Vale destacar, contudo que, embora a divisão entre execução e concepção esteja presente em toda a fábrica, há ainda uma nítida divisão entre a organização do trabalho dos homens e das mulheres. O que se nota é que, apesar de ambos os tipos de trabalho serem pouco qualificados, o trabalho das mulheres é absolutamente manual, seja no back end, seja no CAR, estando sujeito à organização taylorista, enquanto o dos homens é mais ligado à supervisão das máquinas (no front end) ou ao teste de peças e mecanismos (no $\mathrm{CAR}$ ), casos em que a organização taylorista com controles de tempos e movimentos não se aplica. Nesses casos, a produtividade é buscada principalmente através das metas e mecanismos semelhantes, mais próximos das novas técnicas de organização do trabalho.

De outro lado, ao não produzir insumos de alta tecnologia (microssensores, chips, componentes eletrônicos), a fábrica importa a tecnologia em vez de desenvolvê-la internamente. Os efeitos desse processo sobre a qualificação da mão de obra são evidentes: a parte da produção desenvolvida na fábrica não exige trabalhos mais complexos. Essa realidade é claramente percebida pelo presidente do sindicato ao declarar:

Eles querem que os trabalhadores tenham maior escolaridade, mas isso não tem a ver com a prática desses trabalhadores, tem mais a ver com a propaganda das empresas de que estão contratando trabalhadores mais escolarizados. (...) Usam novas tecnologias, mas isto não tem efeitos sobre os trabalhadores. 
A gerente de Recursos Humanos da fábrica confirma $e$ complementa os comentários do líder sindical ao explicitar que a exigência de escolaridade de segundo grau completo "é mais uma tradição, mas não precisa disso". O mais importante é "alguma vivência em chão de fábrica, mesmo que seja em outros setores". Ou seja, alguma disciplina de trabalho.

Isso significa que continua havendo na produção desse setor uma divisão internacional do trabalho que dificulta a utilização de trabalho mais qualificado no Brasil. De acordo com uma das operadoras da empresa visitada:

sempre que vem uma máquina nova vem alguém de fora pra ensinar o técnico aqui, como é que usa; mas eles não consertam não, quando dá algum problema tem que vir alguém de fora de novo. E pra ensinar pra gente não é os daqui que passa, é os que vêm de lá que passa pra gente.

Essas conclusões vêm corroborar os alertas lançados pelos estudos críticos à sociedade do conhecimento, aos quais aludimos na introdução deste artigo. De fato, o que a pesquisa evidencia é um uso das tecnologias que, baseando-se em uma forte divisão internacional, bem como sexual do trabalho, tem implicações nocivas para o conjunto dos trabalhadores brasileiros, relegados especialmente aos trabalhos de execução e, notadamente, para as trabalhadoras, segregadas nas atividades manuais, repetitivas $e$ destituídas de conteúdo; sem oportunidade de carreira, essas trabalhadoras convivem com a gerente de $\mathrm{RH}$, situação que vem corroborar também a polarização do trabalho das mulheres. Elas apontam, assim, para a premência de políticas que favoreçam a produção interna de produtos mais sofisticados da indústria eletrônica, como chips e outros componentes de maior valor agregado e que incentivem as empresas a adotarem formas de organização do trabalho baseadas na qualificação da força de trabalho, de modo a propiciar um uso das tecnologias de informação e comunicação que seja mais favorável aos 
trabalhadores e, sobretudo, às operárias, que têm ficado absolutamente à margem dos benefícios do progresso tecnológico.

\section{Referências bibliográficas}

ANSANElli, S. L. de M. Exigências Ambientais Europeias: Novos Desafios Competitivos para o Complexo Eletrônico Brasileiro. Revista Brasileira de Inovação, Campinas, vol. 10, nº 1, 2010, pp.129-160.

BALBINOT, Z.; MARQUES, R. A. Alianças estratégicas como condicionantes do desenvolvimento da capacidade tecnológica: o caso de cinco empresas do setor eletro-eletrônico brasileiro. Revista de Administração Contemporânea. Rio de Janeiro, vol.13, n.4, 2009, pp.604-625.

BRUSCHINI, C. Fazendo as perguntas certas: como tornar visível a contribuição econômica das mulheres para a sociedade? II Congresso Latino-americano de Sociologia do Trabalho, Águas de Lindóia, 1996. Anais... mimeo.

BRUSCHINI, M. C. A. Trabalho e Gênero no Brasil nos últimos dez anos. Cadernos de Pesquisa [online]. 2007, vol. 37, $\mathrm{n}^{\circ}$ 132, pp.537-572 [http://www.scielo.br/scielo.php?script $=$ sci_arttex\&pid $=$ S0100157420070003000003 - acesso em: nov. de 2013].

BRUSCHINI, C.; LOMBARDI, M. R. Mulheres e homens no mercado de trabalho brasileiro: um retrato dos anos 1990. In: MARUANI, M.; HIRATA, $\mathrm{H}$. As novas fronteiras da desigualdade: Homens e Mulheres no Mercado de Trabalho. São Paulo, Editora SENAC, 2003, pp.323361.

CAstells, M. A sociedade em rede. 4ed. São Paulo, Paz e terra, 1999, vol. 1.

COCKBURN, Cinthia. Machinery of dominance. Women, men and technical know-how. London, Pluto Press. 1985.

DIEESE - Departamento Intersindical de Estatística e Estudos Socioeconômicos e CNM/CUT. O setor eletroeletrônico no Brasil. 2010

[http://www.imfmetal.org/files/10041915024410005/Dorival_Jesus_d o_Nacimento.pdf - acesso em: 11 set 2012]. 
DRUCKER, P. Sociedade pós-capitalista. São Paulo, Pioneira,1994.

DZIEKANIAK. G. e ROVER, A. Sociedade do conhecimento: Características demandas e requisitos. DataGramaZero Revista de Ciência da Informação, vol.12, $\mathrm{n}^{\circ} \quad 5, \quad$ Out. 2011 [http://www.dgz.org.br/out11/F_I_art.htm - acesso em nov. de 2013].

GuiRALDELli, R. Adeus à divisão sexual do trabalho? Desigualdade de gênero na cadeia produtiva da confecção. Soc. estado. 2012, vol.27, $\mathrm{n}^{\circ} \quad 3, \quad$ pp.709-732 [http://dx.doi.org/10.1590/S010269922012000300014 - acesso em: nov. de 2013].

HiRATA, H. Nova divisão sexual do trabalho? Um olhar voltado para a empresa e a sociedade. Coleção Mundo do Trabalho. São Paulo, Boitempo, 2002.

HiRATA, H.; KeRgoAt, D. A divisão sexual do trabalho revisitada. In: MARUANI, M.; HIRATA, H. (Orgs). As novas fronteiras da desigualdade: Homens e mulheres no mercado de trabalho. Senac, São Paulo, 2003, pp.111-125.

HiRATA, H.; Rogerat, C. Technologie, qualification et division sexuelle du travail. Revue française de sociologie. Paris, 1988, vol. 29, n¹, pp.171-192.

KERGOAT, D. Technologie et travail, document de travail. 1981. mimeo.

KERGOAT, D. Masculin/Feminin: Division sexuelle du travail et qualification. Cadres CFDT, Paris, n 313 , 1984, pp.26-29.

KeRgoAT, D.; HiratA, H. Divisão sexual do trabalho profissional $e$ doméstico: Brasil, França e Japão. In: BRUSCHINI, C.; COSTA, A.; HIRATA, H.; SorJ, B. (orgs). Mercado de trabalho e Gênero comparações internacionais. Rio de Janeiro: FGV Editora, 2008, pp.263-279.

LAVINAS, L. Assimetrias de gênero no mercado de trabalho x sistema de proteção social: gargalos brasileiros. I Seminário Internacional Trabalho, cuidado e políticas sociais: Brasil-França em debate. USP e UFRJ/agosto de 2014. Mimeo.

LAVINAS, L. Emprego Feminino: O que Há de Novo e o que se Repete. Dados. vol. 40, n 1 , Rio de Janeiro, 1997 [http://dx.doi.org/10.1590/S0011-52581997000100003 - acesso em: nov. de 2013]. 
LEITE, M. Trabalho e Sociedade em Transformação. Mudanças produtivas e atores sociais. São Paulo, Fundação Perseu Abramo, 2003.

LEITE, M; RIZEK, C. Cadeias, complexos e qualificações. In: LeITE, M. de P.; NeVES, M. de A. (Org.). Trabalho, Qualificação e Formação Profissional. São Paulo/Rio de Janeiro, Alast (Associação LatinoAmericana de Sociologia do Trabalho)/SERT-SP, 1998, vol. 1, pp.4576.

LEITE, M. e SALAS, C. Trabalho e desigualdades sob um novo modelo de desenvolvimento. Tempo Social. Revista de Sociologia da USP, vol. $26, \mathrm{n}^{\circ} 1$, junho de 2014, pp.87-100.

LENCIONI, S. Cisão Territorial da Indústria $e$ integração regional no estado de São Paulo. In: GonÇAlveS, M.; BrandÃo, C.; Galvão, A. (orgs). Regiões e Cidades, Cidades nas Regiões: O desafio Urbano Regional. São Paulo, Editora UNESP, Anpur, 2003, pp.465-475.

LOBO, E. S. A classe operária tem dois sexos - Trabalho, dominação e resistência. São Paulo, Editora Brasiliense, 1991.

LOMBARDI, M. R. Anotações sobre desigualdades de gênero no mercado de trabalho. Seminário Brasil-França Economia Solidária. Unicamp, agosto 2009, Anais... pp.1-25.

MARIGUETTI, A. Industrialização do interior paulista e a territorialização das indústrias de alta tecnologia e pólos tecnológicos - alguns elementos da reestruturação urbana. XII Simpósio Nacional de Geografia Urbana, 2010, Anais..., pp.1-20.

MARUANI, M. Introdução. In: MARUANI, M.; HIRATA, H. (Orgs). As novas fronteiras da desigualdade: Homens e mulheres no mercado de trabalho. Senac, São Paulo, 2003, pp.21-29.

MARUANI, M.; HIRATA, H. (Orgs). As novas fronteiras da desigualdade: Homens e mulheres no mercado de trabalho. Senac, São Paulo, 2003.

OLIVEIRA, S. S. B. de. O processo produtivo da indústria eletroeletrônica e a qualificação dos trabalhadores no pólo industrial de Manaus. Perspectiva [online]. 2006, vol. 24, no 2, pp.689-708 [https://periodicos.ufsc.br/index.php/perspectiva/article/view/1699 acesso em: nov. de 2013]. 
RIFKIN, J. A era do acesso. Ribeirão Preto, SP, Makron Books do Brasil Editora Limitada, 2000.

SCOTT, J. Gênero: uma categoria útil de análise histórica. Revista Educação e Realidade, Porto Alegre, vol. 20, n 2, jul/dez 1990, p.519.

SAMPAIO, D. Relações de gênero na indústria automotiva. A problemática da divisão sexual do trabalho e da visão essencializada da mulher. Um estudo de caso. Dissertação de Mestrado, UFPR, 2007.

SANTOS, T. Divisão sexual do trabalho na indústria calçadista do Vale dos Sinos, Rio Grande do Sul: visibilizando práticas e representações. Revista Mulher e Trabalho. Porto Alegre, vol. 4, 2004, pp.73-84.

SquiRRA, S. Sociedade do Conhecimento. In: MARQUES de Mello, J. e SATHLER, L. Direitos à comunicação na sociedade da informação. São Bernardo do Campo, SP, UMESP, 2005, pp.255/265.

SHAFF, A. A sociedade informática: As consequências sociais da segunda revolução industrial. São Paulo, Unesp, Brasiliense, 1996.

STANCKI, N. Divisão sexual do trabalho: a sua constante reprodução. Paper apresentado no I Ciclo de Debates em Economia Industrial, Trabalho e Tecnologia, 2003, PUC-SP.

TAVARES, Walkyria M. Leitão. A indústria eletrônica no Brasil e seu impacto sobre a balança comercial. Consultoria on line: $<$ http://www2.camara.leg.br/documentos-e-

pesquisa/publicacoes/estnottec/pdf/108604.pdf > . Brasília, novembro de 2001.

TOFFLER, A. A terceira onda. Rio de Janeiro, Record, 1980.

\section{Sites}

http://www.mct.gov.br (consultado em 08/12/2013)

http://www.cnmcut.org.br/ (consultado em 08/12/2013)

http://www.lucianosathler.pro.br/site/images/conteudo/livros/direito_a_co municacao/254-265_sociedade_conhecimento_squirra.pdf (consultado em $10 / 10 / 2014$ ) 
366 Tudo muda, nada muda

http://www.egov.ufsc.br/portal/conteudo/artigo-sociedade-doconhecimento-caracter\%C3\%ADsticas-demandas-e-requisitos (consultado em 10/10/2014)

http://dx.doi.org/10.1590/S0011-52581997000100003 (consultado em 07/10/2014) 